\title{
Comparative analysis of polygalacturonase in the fruit of strawberry cultivars
}

\author{
H.C. Zhou, G. Li, X. Zhao and L.J. Li \\ Zhengzhou Fruit Research Institute, Chinese Academy of Agricultural Sciences, \\ Zhengzhou, China \\ Corresponding author: H.C. Zhou \\ E-mail: zhouhoucheng@caas.cn
}

Genet. Mol. Res. 14 (4): 12776-12787 (2015)

Received April 23, 2015

Accepted July 30, 2015

Published October 19, 2015

DOI http://dx.doi.org/10.4238/2015.October.19.21

ABSTRACT. The role of polygalacturonase (PG) in the development, ripening, and softening of fruit from two strawberry cultivars with different flesh firmness and softening characteristics was compared. Changes in PG activity and gene expression during development, ripening and softening were measured. The $P G$ genes from each cultivar were cloned and analyzed, and were classified with other $P G$ genes using phylogenetic analysis. In Toyonoka fruit, PG activity increased gradually, reaching a peak during the pink stage, and remained at this level during post-harvest softening. Changes in $P G$ gene expression were consistent with $P G$ activity in these softer fruits. In the firmer Sweet Charlie fruits, PG activity was detected during the initial development stage, reaching a peak at the white stage, thereafter decreasing gradually with ripening and remaining at this lower level throughout softening. Changes in $P G$ gene expression and $P G$ activity were not consistent in these fruit. For both Toyonoka and Sweet Charlie PG genes (FaTPG and FaSCPG, respectively), the open reading frame was $1218 \mathrm{bp}$, encoding 405 amino acids. Five different nucleotide sites were observed between the two sequences, leading to two amino acid sequence mutations. FaTPG, FaSCPG, and PG genes from the Fragaria vesca genome were classified into three clades using phylogenetic analysis. The clade containing $P G$ genes involved in fruit 
softening had functional similarity but there were no functional differences between FaTPG and FaSCPG. Differences in PG activity, gene sequence, and gene expression may have led to different roles of $P G$ during ripening and softening in strawberries with different textures.

Key words: Strawberry; Polygalacturonase; Fruit texture; Fruit ripening and softening; Gene expression analysis

\section{INTRODUCTION}

Polygalacturonase (PG), a cell wall hydrolase, can hydrolyze the $\alpha-(1,4)$ glycosidic bond of galacturonic acid residues in the pectin molecule, which can lead to fruit softening through degradation of pectin and disintegration of the cell wall structure of fruits. PG can be divided into exo-PG and endo-PG in terms of its different modes of action. Endo-PG generally refers to fruitripening-specific PG (Hadfield and Bennett, 1998). However, the PG found in strawberry fruits is exo-PG due to fruit ripening and softening (Redondo-Nevado et al., 2001; Salentijn et al., 2003; Villarreal et al., 2008).

An increase in $P G$ activity is closely related to the ripening and softening of fruits. However, large differences in $P G$ activity are detected in the ripening of different types of fruit. Some scholars deem that an increase in PG activity is positively correlated to the softening of fruits and PG accelerates fruit softening (Bonghi et al., 1996; Ali et al., 2004; Villarreal et al., 2008; Liu et al., 2013). However, research has also proved that $P G$ activity is absent during the ripening and softening of some fruits (Cutillas-Iturralde et al., 1993; Nunan et al., 2001; Goulao et al., 2007), which indicates that PG is not a key enzyme in the softening process. Additionally, PG activity and function differ significantly among different cultivars of the same type of fruit. Previous research has discovered that PG is closely associated with fruit softening in soft flesh cases, while it has no relationship with that of fruits with hard flesh (Villarreal et al., 2008). Endo-PG plays a role in the softening of melting and non-melting peach fruit, and its function is not directly related to the firmness of the fruit (Callahan et al., 2004; Manganaris et al., 2006). All these results indicate that there remains doubt as to whether or not there is any correlation between PG activity and the softening of the same type of fruit with different flesh textures and firmness.

At present, large numbers of PGs, which are associated with the ripening and softening of horticultural fruits, have been identified (based on the data from the National Centre for Biotechnology Information, NCBI). The expression patterns of PG in different fruits have also been studied extensively. For example, four PG genes including MAPG1, MAPG2, MAPG3, and MAPG4 were cloned from the fruit of climacteric banana. All these genes are involved in the ripening and softening of banana (Mehar and Nath, 2005). PG genes have also been cloned from two non-climacteric strawberry fruit, Chandler (Redondo-Nevado et al., 2001) and Camarosa (Villarreal et al., 2008), and antisense expression was performed on two genes, FaPG1 and FaPG2. The results revealed that FaPG1 plays a significant role in the softening of the fruit (Quesada et al., 2009). The aforementioned studies verify that PG is involved in the ripening and softening of both climacteric and non-climacteric fruits. As there are no specific peaks in respiratory rate and ethylene concentration during ripening, the strawberry is a type of nonrespiratory climacteric fruit. Its ripening mechanism differs from that of respiratory climacteric fruit. Therefore, the strawberry is an ideal subject material for investigating the development, ripening, and softening of non-climacteric fruits. 
The objective of this study was to compare differences in PG activity, PG sequences, and gene expression during the development, ripening, and softening of fruit from two cultivars of strawberry, and analyze the relationship between PG activity and fruit softening. Furthermore, the molecular phylogenetic relationship of $P G$ was constructed, and used as an approach to reveal the possible role of PG in strawberry softening.

\section{MATERIAL AND METHODS}

\section{Plant material}

Strawberry fruits (Fragaria ananassa cv. Toyonoka and cv. Sweet Charlie) were harvested at different developmental stages: small green fruit (SG), large green fruit (LG), white fruit (W), turning stage fruit (TS), pink fruit $(P)$, and red fruit $(R)$. Additionally, fruit from the red stage that had been maintained at room temperature for $24 \mathrm{~h}$, and at $4^{\circ} \mathrm{C}$ for $24 \mathrm{~h}, 48 \mathrm{~h}$, and $72 \mathrm{~h}$ was used. All fruit was stored at $-20^{\circ} \mathrm{C}$ for detecting change in PG activity. RNA was extracted from fruit at the red stage for gene cloning. Gene expression was analyzed in fruit the small green, large green, white fruit, pink fruit, and red fruit stages, and in plant tissues, such as roots, leaves, and flowers. Upon sampling, the materials were frozen quickly in liquid nitrogen and stored at $-80^{\circ} \mathrm{C}$.

\section{Fruit firmness determination}

Fruit firmness was measured using a TA.XT plus Texture Analyzer (Stable Micro Systems Ltd., London, UK) fitted with a $2 \mathrm{~mm}$ flat probe. Each fruit was penetrated to $6 \mathrm{~mm}$ at a rate of $0.5 \mathrm{~mm} / \mathrm{s}$ and the maximum force developed during the test was recorded. Thirty fruit of each cultivar at each ripening stage were assayed, and each fruit was measured twice on opposite sides of the equatorial zone. The data were processed using Exponent 32 software (http://www. stablemicrosystems.com).

\section{Assay of PG activity}

PG activity was detected according to published methods (Cao et al., 2007). PG activity $\left(\mu \mathrm{g} \cdot \mathrm{h}^{-1} \cdot \mathrm{g}^{-1}\right)$ was expressed as the mass of galacturonic acid generated by the hydrolyzation of polygalacturonic acid, which was catalyzed by $1 \mathrm{~g}$ fresh fruit sample at $37^{\circ} \mathrm{C}$ for $1 \mathrm{~h}$. Three independent extracts were prepared from each condition analyzed per $10 \mathrm{~g}$ fruit sample, and the $P G$ activity of each extract was measured three times.

\section{Gene cloning}

RNA was extracted using the manufacturer protocol supplied with the TRIzol kit (Invitrogen, USA). Using extracted total RNA as the template, CDNA was synthesized using the SMART ${ }^{\mathrm{TM}}$ PCR cDNA Synthesis kit following the manufacturer protocol. After reverse transcriptase was inactivated, the solution was diluted (50-fold) using sterilized ultrapure water and stored at $-20^{\circ} \mathrm{C}$. By adopting the synthesized cDNA as a template, the 5' and 3' cDNA ends were amplified using the Clontech SMART TM RACE cDNAAmplification kit.

According to the expressed sequence tag (EST) ALB58 of the PG gene in the selfdesigned suppression subtraction hybridization (SSH) cDNA library (Zhou et al., 2013), 3' and 5' 
gene specific primers (GSP) were designed using Oligo7.57 and produced by Sangon Biotech (Shanghai, China). The sequences for specific primers and the universal primer (UPM) are listed in Table 1. UPM was produced by mixing long primer ( $45 \mathrm{bp}, 0.4 \mu \mathrm{M})$ and short primer (22 bp, $2 \mu \mathrm{M})$.

The amplification reaction for the polymerase chain reaction (PCR) consisted of the

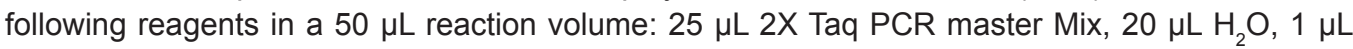
cDNA, $2 \mu \mathrm{L}$ UPM, and $2 \mu \mathrm{L} \mathrm{GSP-PG3} \mathrm{(or} \mathrm{GSP-PG5).} \mathrm{The} \mathrm{reactions} \mathrm{were} \mathrm{performed} \mathrm{at} 94^{\circ} \mathrm{C}$ for 10 min, followed by 40 cycles of $94^{\circ} \mathrm{C}$ for $30 \mathrm{~s}, 65^{\circ} \mathrm{C}$ for $30 \mathrm{~s}$, and $72^{\circ} \mathrm{C}$ for $3 \mathrm{~min}$; and a final extension step at $72^{\circ} \mathrm{C}$ for $10 \mathrm{~min}$. After testing the PCR products using agarose gel electrophoresis, the target fragments were recycled, and T/A clone was performed using a pUCm-T carrier. DNA sequencing was conducted by Sangon Biotech.

\begin{tabular}{ll} 
Table 1. Primer sequences used for RACE cloning genes and quantitative real-time PCR analysis. \\
\hline Code No. & Sequence (5'-3') \\
\hline GSP-PG3 & CAAAGCACCGGGAGATAGCTCTAACAC \\
GSP-PG5 & CGGTTGAGCGCCCATATGTATTCCATC \\
UPM & CTAATACGACTCACTATAGGGCAAGCAGTGGTATCAACGCAGAGT \\
Long & CTAATACGACTCACTATAGGGC \\
Short & CGAGGCTCAATCCAAAAGAG \\
Actin-F & TGGCCACATACATAGCAGGA \\
Actin-R & TGTTGCTAACCAGTCCTCAT \\
PG-F & CGCAGTTGAAGTTGCCCTAT \\
\hline
\end{tabular}

\section{Quantitative real-time PCR}

FaACTIN, a housekeeping gene from strawberry, was applied as an internal control for quantitative real-time PCR (qRT-PCR). The amplification primers Actin-F and Actin-R of FaACTIN and the amplification primers PG-F and PG-R of $P G$ were designed and the sequences of these primers are detailed in Table 1. RNA was extracted using a TRIzol kit (Invitrogen) and then cDNA was synthesized using an AMV First Strand cDNA Synthesis kit. Afterwards, the cDNA sample was diluted (eight-fold), applied as the template, and detected. The PCR cycling conditions included 2 min of initial denaturation at $95^{\circ} \mathrm{C}$, followed by 40 cycles of $95^{\circ} \mathrm{C}$ for $10 \mathrm{~s}$ and $60^{\circ} \mathrm{C}$ for $40 \mathrm{~s}$. Each sample was run in triplicate for qRT-PCR. After one-fold, five-fold, 25-fold, 125-fold, and 625 -fold sample dilution, standard curves were drawn by selecting the five points. According to the $C T$ values of the curves, the relative expression of the genes was determined. The data were processed using MS-Excel ${ }^{\circledR} 2007$.

\section{Establishment of a phylogenetic tree for PG}

Based on the amino acid sequence deduced from the $P G$ gene cloned in the aforementioned experiments, BLASTP was performed for the Fragaria vesca genome, which was selected from the plant genome database (http://phytozome.jgi.doe.gov/pz/portal.html). Sequences with $E \leq 10^{-6}$ were considered as $P G$ genes and the corresponding amino acid sequences were downloaded. Then, the phylogenetic tree of PG was constructed using a neighbor-joining $(\mathrm{NJ})$ model in the MEGA 5.2 software and calibrated through the use of a Poisson model: a bootstrap test was repeated 1000 times. 


\section{RESULTS}

\section{Change in firmness during development and ripening of strawberry fruit}

The rate of decrease in firmness of fruit from the two strawberry cultivars varied significantly during development and ripening. The firmness of Toyonoka fruit reduced more quickly than that of Sweet Charlie fruit; the firmness of the former was half that of the latter from the pink fruit stage to the red fruit stage (Figure 1). Toyonoka, a fruit with soft flesh, is soft after ripening and completely softens after being maintained at room temperature for $24 \mathrm{~h}$. While, with hard flesh, Sweet Charlie fruit can generally be stored for between 3 and 5 days.

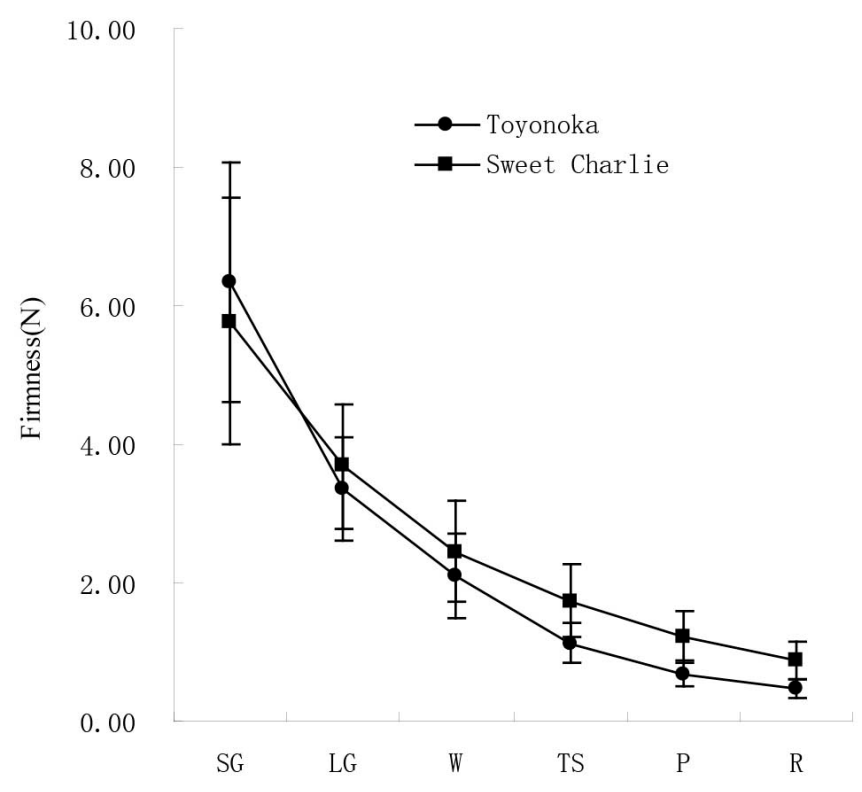

Figure 1. Changes of firmness during development and ripening of two cultivars of strawberry fruits. Small green fruit (SG), Large green fruit (LG), White fruit (W), Turning stage (TS), Pink fruit (P), Red fruit (R).

\section{Change in PG activity during development, ripening, and softening of strawberry fruit}

PG activity varied during the development, ripening, and post-harvest softening of fruit from the two strawberry cultivars, with almost completely contrasting results (Figure 2). In Toyonoka fruit, PG activity was low during the small green stage and was absent during the large green and white fruit stages. With ripening of Toyonoka fruit, PG activity gradually increased and reached a peak during the pink fruit stage, and was maintained at a high level until complete post-harvest softening of the fruit. In contrast, in Sweet Charlie fruit, PG activity was detected during the initial period of development and peaked as the fruit progressed to the white fruit stage, then it decreased during the ripening of the fruit and remained at a low level until complete softening of the fruit. 

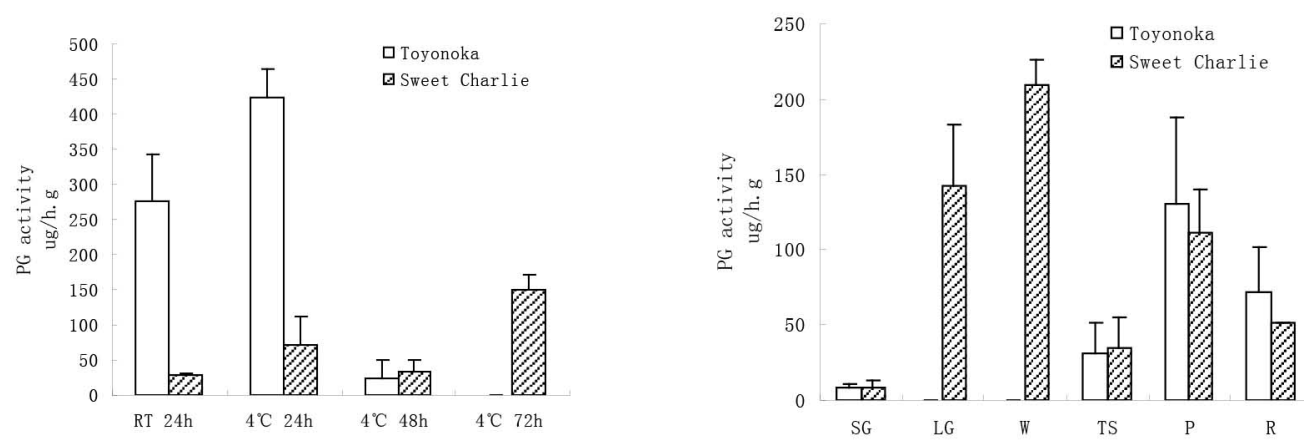

Figure 2. Changes of PG activity during development and ripening and softening of strawberry fruits. Small green fruit stage (SG), Large green fruit stage (LG), White fruit stage (W), Turning stage (TS), Pink fruit stage (P), Red fruit stage $(\mathrm{R})$, Room temperature (RT).

\section{$P G$ gene cloning and sequence analysis}

GSPs were designed based on the sequence (662 bp) of the ALB58 segment of the PG gene from the SSH cDNA library and the CDNA sequences of the $5^{\prime}$ and $3^{\prime}$ ends were obtained using the rapid amplification of cDNA ends (RACE) method. The cDNA of the PG gene was acquired after sequence assembly. The full-length cDNA of the Toyonoka PG gene (FaTPG) contains $1496 \mathrm{bp}$, in which there is a complete open reading frame (ORF) of $1218 \mathrm{bp}$ encoding 405 amino acids. The full-length cDNA of the Sweet Charlie PG gene (FaSCPG) consists of $1493 \mathrm{bp}$ and also contains a complete ORF of 1218 bp encoding 405 amino acids (Figure 3). BLAST similarity analysis revealed that the nucleotide sequences of FaTPG and FaSCPG reached $99.26 \%$ similarity, with the main differences observed in the untranslated region (UTR) of the $3^{\prime}$ end. The five different nucleotides in the ORF induced mutation of two amino acids at the positions of 95 and 121. Based on comparison with the amino acid sequences of other cultivars of strawberry, it was revealed that both mutations occurred on FaSCPG, where valine $(V)$ became alanine $(A)$ (hydrophobicity reduced) and glutamate $(E)$ transformed to lysine $(K)$ (the amino acid became basic; Figure 3). The correlation between the two amino acid mutations and $P G$ activity requires further exploration.

The 3'-UTR sequences of FaTPG and FaSCPG mainly differed from the PG sequences of the Elsanta and Camarosa cultivars and the wild species, Fragaria chiloensis and $F$. vesca. Compared with FaTPG and FaSCPG, the F. chiloensis PG sequence (EF441274) has an additional 78 bp in front of its poly(A), Camarosa PG (DQ458990 and DQ458991) displays a shorter 3'-UTR and has 235 bp less in front of its poly(A), and there are also 85 bp deletions in DQ458991 in the ORF. The $P G$ sequence of $F$. vesca is also significantly different from that of FaTPG and FaSCPG, with 30 bp deletions in the ORF.

Similarity analysis of FaTPG and FaSCPG amino acid sequences in NCBI revealed that both have similar amino acid sequences to $P G$ sequences in other strawberry fruit, with more than $99 \%$ similarity. Meanwhile, the 85 bp deletion in the PG amino acid sequence of the Camarosa (ABE77146) cultivar induced a frame shift mutation. Therefore, the encoded protein lost PG activity. FaTPG and FaSCPG exhibited 99\% similarity with the PG sequence of $F$. chiloensis (ABR26683) and $78 \%$ similarity with that of $F$. vesca (XP_004305963). 


\begin{tabular}{|c|c|c|}
\hline FaSCPG & AYRSRVACELAPGLF DVTSERYGGKPNIDISQPELANAR & 80 \\
\hline FaTPG & AYA SRVACQELAPGLF DVTSERYGGRENTDISQRLZANAWKDACAZTIPSRVIVPRGTFQLRG & 80 \\
\hline AAP37458 & 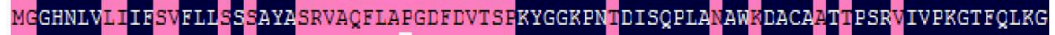 & 80 \\
\hline ABR26683 & 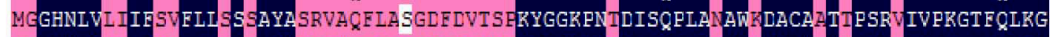 & 80 \\
\hline ABE77145 & 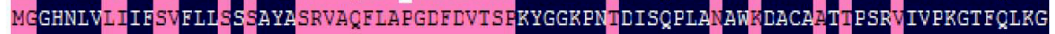 & 80 \\
\hline ABE77146 & 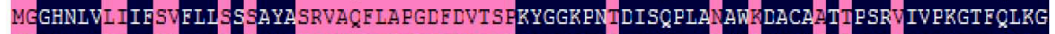 & 80 \\
\hline XP_004293444 & SAYASRVACEFLA PGDF DVISEKYGGKENIDISQRLAN & 80 \\
\hline XP_004305963 & & 69 \\
\hline FaSCPG & SWKLNDCNKNENGGLAINVRFD & 160 \\
\hline FaTPG & 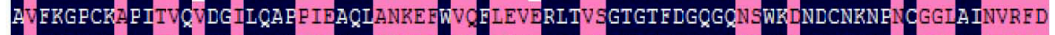 & 160 \\
\hline AAP37458 & LQAEPIAAQLANKE AWVOALEVERLTVSGTGTFDGQGQNSWKLNDCNKNENCGGIAINVRED & 160 \\
\hline ABR26683 & LQAEPIBAQLANKE IVVQHLEVERLTVSGTGT FDGQGQNSWKLNDCNKNENGGGIAINVRED & 160 \\
\hline ABE77145 & 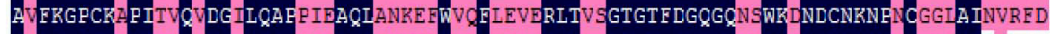 & 160 \\
\hline ABE77146 & DEILQAEPIBAQIANKE FWV QGLEVERLTVSGTGTFDGQGQNSWKDNDCNKNENGGGIAIGVNIL & 160 \\
\hline XP_004293444 & 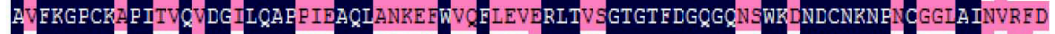 & 160 \\
\hline $\mathrm{XP}_{-} 004305963$ & BNDCNRNEKGSSIAINI & 149 \\
\hline FaSCPG & KVKISLVRDVTSLNSKNFHFNILGCEHLTFQ्रHVIVKAPGDSSNTLGIHMGRSTEINITDTNIGTGDDCISVGDGTRQLTV & 240 \\
\hline FaTPG & KVKISLVRDVISLNSKNFHFNILGCEHLTFQHVTVKAPGDSSNTDGIHMGRSTEINITDTNIGTGDDCISVGDGTRQLTV & 240 \\
\hline A.AP37458 & RVKNSLVRDVTSLNSKNFHFNILGCEHLTEQHVIVRAPGDSENTDGIHMGRSTRINITDTNIGTGDDCISVGDGTRCLTV & 240 \\
\hline ABR26683 & KVRISLVRDVTSLNSKNFHFNILGCEHLTEQHVTVRAPGDSSNTDGIHMGRSTEINITDTNIGTGDDCISVGDGTRQLTV & 240 \\
\hline ABE77145 & RVKISLVRDVTSLNSKNFHFNILGCEHLTFCHVIVRAPGDSPNTLGIHMGRSTRINITDTNIGTGDDCISVGDGTRQLTV & 240 \\
\hline ABE77146 & 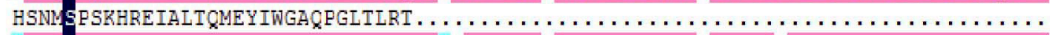 & 191 \\
\hline XP_004293444 & KVKISIVRDVTSLNSKNFHFNILGCEHLTECHVT IKAPGLS PNTDGIHMGRSTGINIT DMNIGTGDDCISVGDGTRQLTV & 240 \\
\hline XP_004305963 & SVRHSLVKDVTSLNSKNFHVNVLGCEQLTFCHFTVKAPGDSINTDGIHIGRSIGINITDTNIGTGDDCISIGDGIKCLII & 229 \\
\hline FaSCPG & SRVSCGPGHGISIGSIGRYLNEDLVSGLNIRLCTLSNTLNGVRIRT FASPRATTASDIHFERITMNNVANPVIIDCEYC & 320 \\
\hline FaTPG & SKVSCGPGHGISIGSLGRYDNEDLVSGLNIRDCTLSNTLNGVRIKT PASPRATTASDIHFERITMNNVANPVIIDCEYY & 320 \\
\hline A.AP37458 & SKVSCGPGHGISIGSLGRYDNEDLVSGLNIRDCTLSNTLNGVRIRTF PASPRATTASDIHFERITMNYVANPVIIDCEYC & 320 \\
\hline ABR26683 & SKVSCGPGHGISIGSIGRYDNEDLVSGLNIRDCTLSNTLNGVRIKTF PASPKATFASDIHFERITMNNVANPVIIDCEYC & 320 \\
\hline ABE77145 & SKVSCGPGHGISIGSLGRYDNEDLVSGLNIRLCTLSNTLNGVRIRT FASPRATTASDIHFERITMNNVANPVIIDQEYC & 320 \\
\hline ABE77146 & 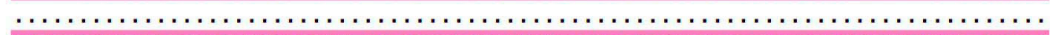 & 191 \\
\hline XP_004293444 & SKVSCGPGHGISIGSLGRYDNEDLVSGLNIRLCTLSNTLNGVRIKT FASPKATTASDIHFERITMNNVANEVLIDQEYC & 320 \\
\hline XP_004305963 & NKVTCGPGHGISIGSIGRYNNELHVTGINVKDCI ISNTMNGVRIKTWENSE IATTASDIHFEHITMNNVGNEIL IDCEYC & 309 \\
\hline FaSCPG & PWGQCNRQIIPSKVRISNVSFKNIIGTTSTAEALRIVCARGL HCDQVVIGDIDIRLSGKGTLTSHCANVQPTTITRVPPFLA & 400 \\
\hline FaTPG & PWGQCNRCIIPSKVRISNVSFKNIIGTTSTAEALRIVCARGL HCDQVVISDIDLKLSGKGTLTSHCANVQDETITRVPPPLA & 400 \\
\hline AAP37458 & PWGQCNRQIPSKVRISNVSFKNIIGTTSTAEALRIVCARGLHCDQVVISDIDLKLSGKGTLTSHCANVQPTITRVPPPLA & 400 \\
\hline ABR26683 & 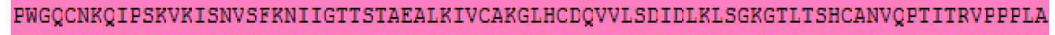 & 400 \\
\hline ABE77145 & 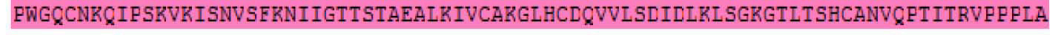 & 400 \\
\hline ABE77146 & 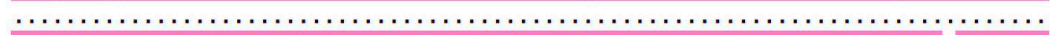 & 191 \\
\hline XP_004293444 & PWGCQCNRQIPSKVRISNVSFKNIIGTTSTAEALRIVCARGLHCDQVVISDIDLRLSGKGTLTSHCANVQRET IARVPPPLA & 400 \\
\hline XP_004305963 & PYGCCNTQTPSKVRISNVSEKNIRGTITTAEAVR IVCARGLPCDKVVLSDIDLKITGKGTLTSQCANVQPTITQVPCALA & 389 \\
\hline FaSCPG & CATK & 404 \\
\hline FaTPG & CATK & 404 \\
\hline A.AP37458 & CATK & 404 \\
\hline ABR26683 & CATK & 404 \\
\hline ABE77145 & CATK & 404 \\
\hline ABE77146 & $\ldots$ & 191 \\
\hline XP_004293444 & CATK & 404 \\
\hline XP_004305963 & & \\
\hline
\end{tabular}

Figure 3. Alignment of deduced amino acid sequences of PG from different strawberry fruits. 
BLAST analysis was performed on the CDNA sequences of FaTPG and FaSCPG in the F. vesca genome database (http://www.phytozome.net/). The results indicated that FaSCPG and FaTPG were matched with the gene 21638-v1.0-hybrid, which is positioned on the No. 3 chromosome with a total length of $1948 \mathrm{bp}$ and positioned between 3,516,202 to 3,518,149 bp. The gene was composed of four exons and three introns, and there were $1218 \mathrm{bp}$ in the translated region encoding 405 amino acids.

\section{PG expression patterns in the development and ripening stages}

The cloned $P G$ gene was used to analyze expression patterns during the development and ripening of fruit from two cultivars of strawberry (Figure 4). The relative expression levels of $P G$ genes were low in vegetative tissues, such as roots, leaves, flowers, etc. With the ripening of the fruit, expression increased rapidly, reaching a peak during the pink fruit stage, after which expression decreased slowly. Toyonoka fruit showed a high level of $P G$ expression during the entire red stage due to the rapid softening of the fruit, while $P G$ expression in Sweet Charlie fruit reduced sharply to a low level at the entire red stage (contributed to by the slow softening of the fruit). $P G$ expression showed consistent trends in the ripening fruit of the two cultivars; however, compared with $P G$ expression in vegetative tissues, the relative expression of $P G$ during the ripening process of Toyonoka fruit was more 10 times higher than expression observed in Sweet Charlie fruit during comparable stages (Figure 4).

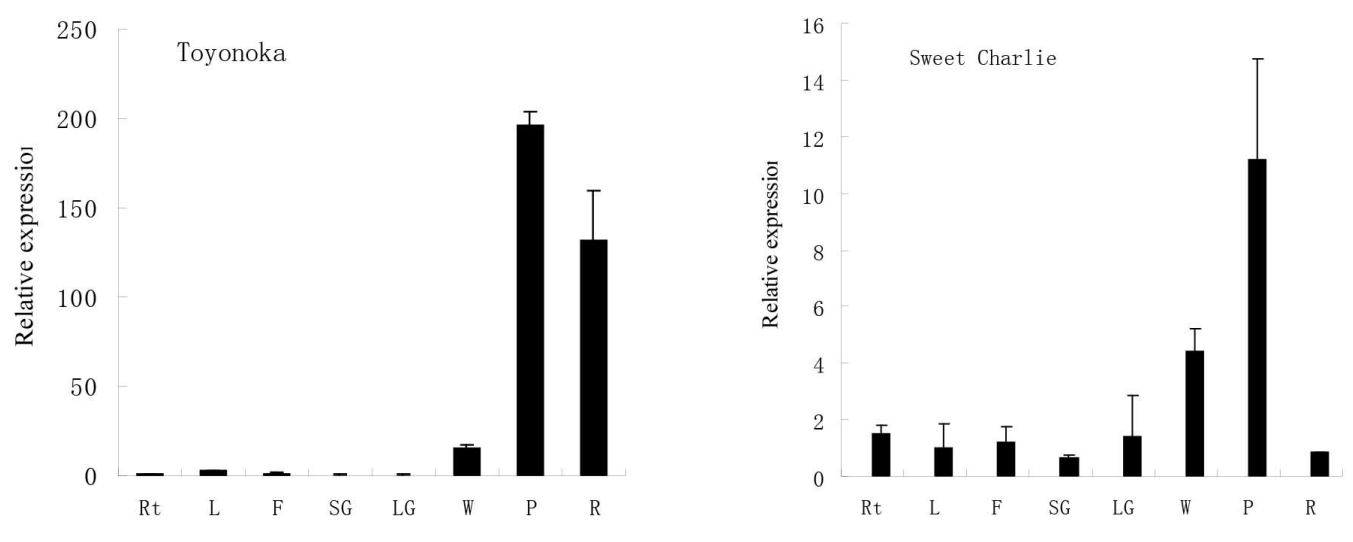

Figure 4. Expression analysis of $P G$ genes during development and ripening of strawberry fruits by qRT-PCR. Root $(R t)$, Leaf (L), Small green fruit stage (SG), Large green fruit stage (LG), White fruit stage (W), Pink fruit stage (P), Red fruit stage $(R)$

\section{PG cluster analysis}

The phylogenetic tree was constructed from the deduced amino acid sequences for FaTPG, FaSCPG, PGs from the fruit of $F$. ananassa and $F$. chiloensis, and $P G$ s from the whole genome of $F$. vesca. $P G$ in $F$. vesca ( $F v P G)$ represents a gene family containing $57 F v P G s$ in the genome. The PG cladogram of FvPGs, FaTPG, FaSCPG, and PGs of other strawberry fruit was divided into three main clades (Figure 5). On one of the clades, FVPGs genes, including mrna21638.1-v1.0-hybrid, mrna01127.1-v1.0-hybrid, mrna14305.1-v1.0-hybrid, mrna20575.1- 
v1.0-hybrid, and mrna20566.1-v1.0-hybrid, clustered together with FaTPG and FaSCPG (Figure 5), indicating that other genes close to FaTPG and FaSCPG are possibly fruit $P G s$.

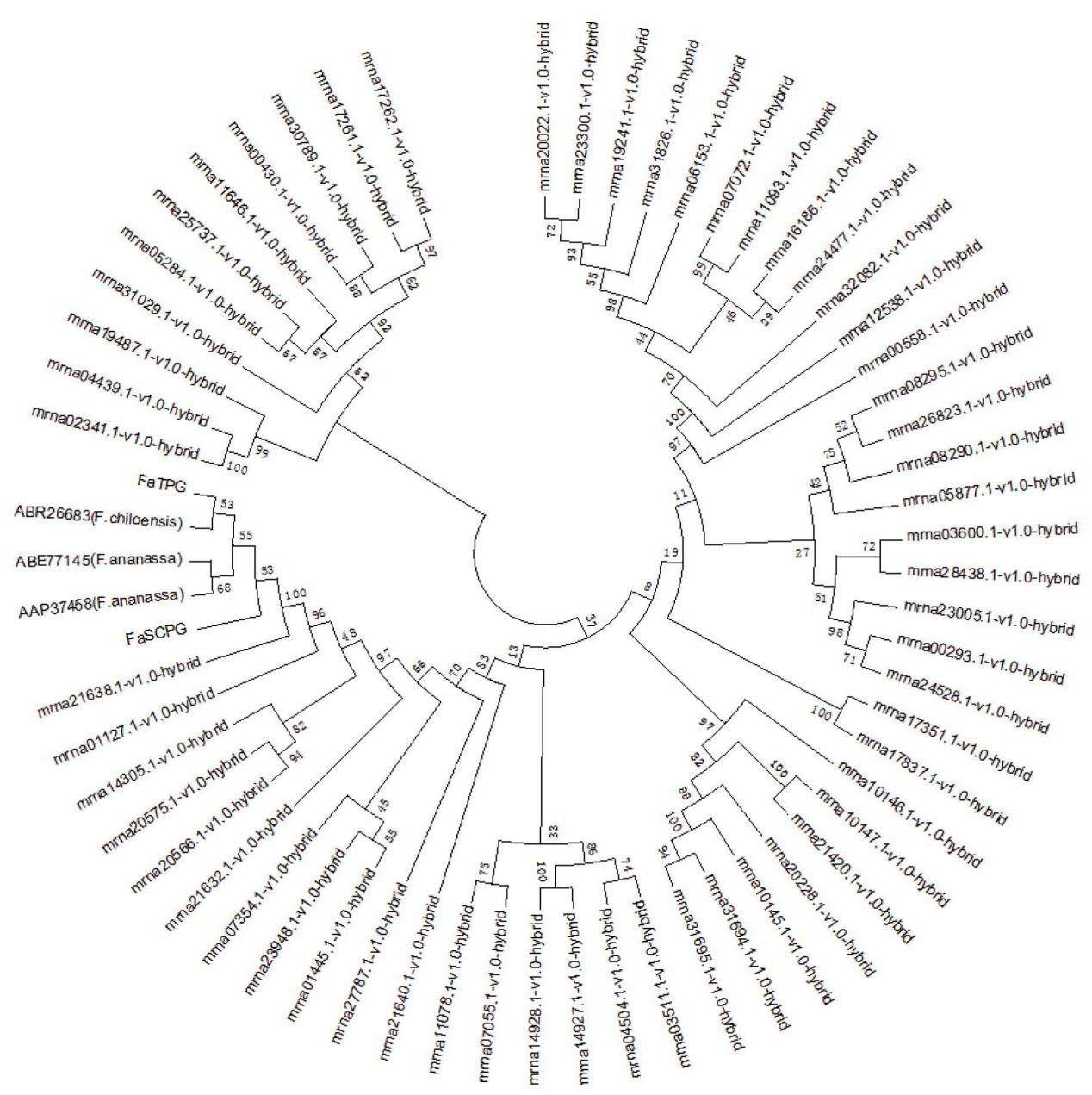

Figure 5. Phylogenetic tree of PG from F. vesca genome and other Fragaria species

\section{DISCUSSION}

Owing to the limited storage period, transportation distance, short shelf-life, and rapid softening and deterioration of fruit following harvest, which reduces edible quality, the production of strawberry fruit is constrained. Therefore, studying the softening mechanism of the fruit, discovering the genes contributing to longer periods of storage and longer transportation distances, and breeding this type of fruit is deemed important. In the current study, two cultivars of strawberry, Toyonoka and Sweet Charlie, with different texture fruit and different storage conditions were analyzed. The relationships between the changes in firmness and PG activity, as well as gene 
expression, were investigated during development, ripening, and softening of the fruit. In addition, the PGs from the two cultivars were cloned, which provided a basis for further detection of $P G$ 's role in strawberry fruit.

The increase in PG activity was closely related to the ripening and softening of the fruit. However, different PG activity was observed during the ripening of the fruit from the two different cultivars. Furthermore, PG activity differed significantly among the fruit from different cultivars. The differences in PG activity among different cultivars are possibly due to the different softening functions of $P G$. Owing to the different composition and spatial structure of the pectic polysaccharides in various fruit species, the softening mechanism can differ significantly (Tong et al., 2011). This was demonstrated in the current study by the different trends in PG activity during the ripening and softening of strawberry fruit from the Toyonoka cultivar with its soft flesh and from the Sweet Charlie cultivar with its harder flesh. With the ripening of Toyonoka fruit, PG activity increased and remained at a high level during softening; in contrast, the PG activity of Sweet Charlie fruit reached its peak at the beginning of the ripening (white fruit stage) and then decreased throughout the ripening and softening of the fruits to finally stabilize at a low level.

The expression patterns of $P G$ in the fruit of the two strawberry cultivars were the same. The changes in $P G$ expression were related to changes in the firmness and softening speed in the fruit of the two strawberry cultivars. With the ripening of the fruit, the relative expression of PG increased. However, $P G$ expression in Toyonoka fruit was higher than that in Sweet Charlie fruit. Inevitably, the structural differences in the $P G$ genes from the fruit of the two cultivars are likely to have resulted in different functions of $P G$ in the softening of the fruit. By cloning and sequencing the $P G$ gene from the fruit of both cultivars, it was revealed that the FaSCPG and FaTPG genes showed five nucleotide mutation points in the ORF. Among which, there were two non-synonymous mutation points. The correlation between the two mutations with PG activity and the softening of the fruit requires further study.

The correlation between changes in PG activity (Figure 2) and changes in PG expression (Figure 4) during the development and ripening of the fruit from the two cultivars were compared. The results demonstrate that PG activity of Toyonoka fruit showed a consistent change with that of FaTPG expression, indicating that FaTPG is probably one of the major genes encoding $P G$. However, the change in PG activity in Sweet Charlie fruit did not conform to that of FaSCPG expression, reflecting that the FaSCPG gene possibly encodes an inactive enzyme, or was expressed by other genes in the gene family (Villarreal et al., 2008). As PG has multiple isozymes, it is likely to show different roles in the ripening and softening of the fruit.

Based on the above analysis, although PG was closely associated with the softening of strawberry fruit, it played different roles in the ripening and softening of fruit from different cultivars. PG has been shown to be a key enzyme in the softening of soft fruit and its function is maintained during the entire softening process (Figueroa et al., 2008). While, with regard to hard fruit, PG is possibly involved in the initiation of fruit ripening instead of the initiation of softening and merely functions as a start-up enzyme (Redondo-Nevado et al., 2001).

PGs from plants are a multi-gene family and there are 66 PG members in the Arabidopsis thaliana genome (Kim et al., 2006). Members of the $P G$ multi-gene family were expressed at different stages and in different tissues during the development of plants (Kim et al., 2006). They mainly participated in the ripening of fruit but they were also associated with cell spreading, cell separation, development, and lignification (Kim et al., 2006). Therefore, PG has been a research focus in the development of plants and the ripening and senescence of fruits. Performing cluster 
analysis for fruit $P G s$, in terms of phylogenetic relationships, is significant when studying the differences between the roles of PGs. Hadfield and Bennett (1998) divided the PG genes of 20 plants into three clades $(A, B$, and $C)$ and considered that the $P G s$ on $A$ and $B$ are related to the ripening and shedding of fruits, while those on $\mathrm{C}$ are exo-PGs associated with pollen development. Park et al. (2008) divided PG genes of plants into five clades. Zhang and Cao (2010) analyzed the molecular phylogenetic relationship of the $P G$ gene families of a plant, a bacterium, and a fungal species. $P G$ genes from 46 plants were also divided into three clades, and the results were in agreement with the results of Hadfield and Bennett (1998). Wei et al. (2011) carried out phylogenetic analysis of $48 P G$ genes that participate in the ripening and softening of fruits. The results revealed that $P G$ genes involved in the softening of fruits were distributed on all three clades. The endo- $P G$ genes of clades $A$ and $B$ differed significantly from the exo- $P G$ genes of clade $C$, considering their functions. Genes with a close evolutionary relationship exhibited similar functions. Furthermore, $P G$ genes from clade A played an important role in the softening of fruits, while $P G$ genes from clade $B$ were not involved in the softening of fruits with soft flesh (Wei et al., 2011). This indicated that the $P G$ genes on the two clades were apparently different in structure, which therefore induced different functions (Wei et al., 2011).

In the current study, FaSCPG and FaTPG, clustered on clade C with F. chiloensis, and $F$. vesca, which are different species of Fragaria, reflecting their close genetic relationship, and all members of the clade, display exo-PG function. However, the analysis did not show further functional differences among the different varieties. The phylogenetic analysis of FaSCPG, FaTPG, and PGs from the F. vesca genome illustrated that there are 57 PGs in the F. vesca genome, which were clustered on different clades, and therefore, displayed various functions. Among the 57 $P G s$, five $P G s$, including mrna21638.1-v1.0-hybrid, which clustered with the fruit $P G s$, are probably involved in the ripening and softening of fruit.

In conclusion, $P G$ activity, $P G$ gene expression, and the gene sequences of $P G$ from different cultivars of strawberry fruit differed. These differences have led to different roles of $P G$ in the ripening and softening of strawberry fruit. PG is a key enzyme for the softening of strawberry fruit with soft flesh, while it is merely the start-up enzyme for the ripening of strawberry fruit with hard flesh.

\section{Conflicts of interest}

The authors declare no conflict of interest.

\section{ACKNOWLEDGMENTS}

Research supported by the Agricultural Science and Technology Innovation Program (CAAS-ASTIP-2015-ZFRI) and the Foundation and Advanced Technology Program of He'nan Province (\#132300410034).

\section{REFERENCES}

Ali ZM, Chin LH and Lazan H (2004). A comparative study on wall degrading enzymes, pectin modifications and softening during ripening of selected tropical fruits. Plant Sci. 167: 317-327.

Bonghi C, Pagni S, Vidrih R, Ramina A, et al. (1996). Cell wall hydrolases and amylase in kiwifruit softening. Postharvest Biol. Technol. 9: 19-29. 
Callahan AM, Scorza R, Bassett C, Nivkerson M, et al. (2004). Deletions in an endopolygalacturonase gene cluster correlate with non-melting flesh texture in peach. Funct. Plant Biol. 31: 159-168.

Cao JK, Jiang WB and Zhao YM (2007). Experiment guidance of postharvest physiology and biochemistry of fruits and vegetables. China Light Industry Press, Beijing, 84-87.

Cutillas-Iturralde A, Zarra I and Lorences EP (1993). Metabolism of cell wall polysaccharides from persimmon fruit. Pectin solubilization during fruit ripening occurs in apparent absence of polygalacturonase activity. Physiol. Plant. 89: 369-375.

Figueroa CR, Pimentel P, Gaete-Eastman C, Moya M, et al. (2008). Softening rate of the Chilean strawberry (Fragaria chiloensis) fruit reflects the expression of polygalacturonase and pectate lyase genes. Postharvest Biol. Technol. 49: 210-220.

Goulao LF, Santos J, De Sousa I and Oliveiera CM (2007). Patterns of enzymatic activity of cell wall-modifying enzymes during growth and ripening of apples. Postharvest Biol. Technol. 43: 307-318.

Hadfield KA and Bennett AB (1998). Polygalacturonases: many genes in search of a function. Plant Physiol. 117: 337-343.

Kim J, Shiu SH, Thoma S, Li WH, et al. (2006). Patterns of expansion and expression divergence in the plant polygalacturonase gene family. Genome Biol. 7: R87.

Liu JA, He HJ, Guo SG, Zhang HY, et al. (2013). Physiological and biochemical mechanism for watermelon fruit ripening and softening. J. Fruit Sci. 30: 813-818.

Manganaris GA, Vasilakakis M, Diamantidis G and Mignani I (2006). Diverse metabolism of cell wall components of melting and non-melting peach genotypes during ripening after harvest or cold storage. J. Sci. Food Agric. 86: 243-250.

Mehar HA and Nath P (2005). Expression of multiple forms of polygalacturonase gene during ripening in banana fruit. Plant Physiol. Biochem. 43: 177-184.

Nunan KJ, Davies C, Robinson SP and Fincher GB (2001). Expression patterns of cell wall-modifying enzymes during grape berry development. Planta 214: 257-264.

Park KC, Kwon SJ, Kim PH, Bureau T, et al. (2008). Gene structure dynamics and divergence of the polygalacturonase gene family of plants and fungus. Genome 51: 30-40.

Quesada MA, Blanco-Portales R, Posé S, García-Gago JA, et al. (2009). Antisense down-regulation of the FaPG1 gene reveals an unexpected central role for polygalacturonase in strawberry fruit softening. Plant Physiol. 150: 1022-1032.

Redondo-Nevado J, Moyano E, Medina-Escobar N, Caballero JL, et al. (2001). A fruit-specific and developmentally regulated endopolygalacturonase gene from strawberry (Fragaria x ananassa cv. Chandler). J. Exp. Bot. 52: 1941-1945.

Salentijn EMJ, Aharoni A, Schaart JG, Boone MJ, et al. (2003). Differential gene expression analysis of strawberry cultivars that differ in fruit firmness. Physiol. Plant. 118: 571-578.

Tong ZG, Wang F, Gao ZH, Zhou J, et al. (2011). Advances in research on the relationship between pectolytic enzymes and fruit softening. J. Fruit Sci. 28: 305-312.

Villarreal NM, Rosli HG, Martínez GA and Civello PM (2008). Polygalacturonase activity and expression of related genes during ripening of strawberry cultivars with contrasting fruit firmness. Postharvest Biol. Technol. 47: 141-150.

Wei X, Liu WS, Liu N, Zhang QP, et al. (2011). Phylogenetic analysis and genomic localization of polygalacturonase genes related to fruit softening. Acta Hortic. Sin. 38: 1791-1799.

Zhang T and Cao JS (2010). Molecular evolution of the polygalacturonase gene family. J. Agric. Biotechnol. 18: 174-180.

Zhou HC, Li G, Zhao X, Wang ZC, et al. (2013). Construction of suppression subtractive hybridization (SSH) cDNA library from two developmental stages of Fragaria ananassa fruit and expression analysis of related genes. J. Agric. Biotechnol. 21: 641-649. 